\title{
Dielectric dispersion and thermodynamic behavior of stearic acid binary mixtures with alcohol as co-solvent using time domain reflectometry
}

\author{
M. Maria Sylvester*, T. Ganesh ${ }^{\dagger, \|}$, D. J. S. Anand Karunakaran*, P. Senthilkumar, \\ Praveen G. Hudge $\mathrm{\S}^{\S}$ and A. C. Kumbharkhane" \\ *PG \& Research Department of Physics, Bishop Heber College, Bharthidasan University \\ Tiruchirapalli 620 017, Tamil Nadu, India \\ ${ }^{\dagger} P G \&$ Research Department of Physics, Rajah Serfoji Government College \\ Bharthidasan University Thanjavur 613 005, Tamil Nadu, India \\ Department of Physics, Saranathan College of Engineering \\ Tiruchirapalli 620 012, Tamil Nadu, India \\ $\S_{\text {Department of Physics, S. I. C. E. Society's Degree College of Arts }}$ \\ Science and Commerce, Ambernath, Thane, Maharashtra, India

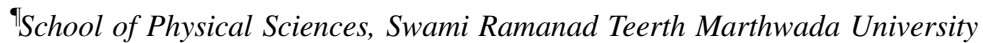 \\ Nanded, Maharashtra, India \\ $\|_{\text {tgsastra@gmail.com }}$
}

Received 10 May 2017; Revised 15 July 2017; Accepted 28 July 2017; Published 23 August 2017

\begin{abstract}
Dielectric permittivity and relaxation dynamics of binary and ternary mixture of stearic acid on various concentration and their thermodynamic effects are studied. The static dielectric constant $\left(\varepsilon_{0}\right)$, dielectric permittivity $\left(\varepsilon^{\prime}\right)$ and dielectric loss $\left(\varepsilon^{\prime \prime}\right)$ are found by bilinear calibration. The relaxation time $(\tau)$, dielectric strength $(\Delta \varepsilon)$ and the excess permittivity $\left(\varepsilon^{E}\right)$ are found. The thermodynamic parameters such as enthalpy $(\Delta H)$, entropy $(\Delta S)$ and Gibb's free energy $(\Delta G)$ are evolved. The significant changes in dielectric parameters are due to the intramolecular and intermolecular interactions in response to the applied frequency. The permittivity spectra of stearic acid-alcohol in the frequency range of $10 \mathrm{MHz}$ to $30 \mathrm{GHz}$ have been measured using picoseconds Time Domain Reflectometry (TDR). The dielectric parameters $\left(\varepsilon_{0}, \varepsilon^{\prime}, \varepsilon^{\prime \prime}\right)$ are found by bilinear calibration method. Influence of temperature in intermolecular interaction and the relaxation process are also studied. The FT-IR spectral analysis reveals that the conformation of functional groups and formation for hydrogen bonding are present in both binary and ternary mixtures of stearic acid.
\end{abstract}

Keywords: TDR; dielectric relaxation; stearic acid; thermodynamic parameters; FT-IR.

\section{Introduction}

Fatty acids esterifying to glycerol are the main constituents of oils and fats. Most commodity oils contain fatty acids with carbon chain length between $\mathrm{C}_{16}$ and $\mathrm{C}_{22}$ with $\mathrm{C}_{18}$ fatty acid which are most commonly found in nature. The basic structure of $\mathrm{C}_{18}$ fatty acid consists of a hydrophobic hydrocarbon chain with 18 carbon (saturated or unsaturated) as a hydrophobic polar group at one end. The most reactive sites in fatty acid molecules are the carboxyl group and the double bond which are important in the formation of structures. ${ }^{1}$ The behavior of monolayers of fatty acids and their related LB films may be the most extensively studied systems for both research and application. ${ }^{2,3}$ The electrostatic interaction between the head group and the divalent cation is the most important factor in stabilizing the long-range structure. The stabilization depends on the interaction between the hydrophobic tail groups. ${ }^{4}$ Recent findings highlight the interest of using fatty acids as "green surfactants" with original properties for various applications such as petrochemical, washing, environmental clean-up, material recovery processes, and drug delivery. ${ }^{5-7}$ The formation of micelles and vesicles in aqueous solution due to mixing of unsaturated acid are reported by various authors. ${ }^{8}$ Beyond self-assembly driven by intermolecular forces, the study of macroscopic properties of these peculiar fatty acid assemblies have been a subject of growing interest.

Dielectric studies have been carried out extensively to understand the intermolecular interactions and the dynamics of liquid mixture by TDR method..$^{9-12}$ The formations are significant changes to the extent of intermolecular or intramolecular interactions in solution. ${ }^{13-15}$ The precise permittivity data of binary and ternary mixtures are necessary for understanding the nature of intermolecular interactions and structural rearrangement. Accurate interpretations of dielectric behavior of various binary and ternary mixtures are important key to establish a relationship between bulk properties

This is an Open Access article published by World Scientific Publishing Company. It is distributed under the terms of the Creative Commons Attribution 4.0 (CC-BY) License. Further distribution of this work is permitted, provided the original work is properly cited. 
and molecular parameters. ${ }^{16-21}$ Dielectric spectroscopy offers valuable insights into the microdynamics of fluctuating hydrogen bonds in liquids. ${ }^{22,23}$ This work is an attempt on the influence of co-solvent on stearic acid mixture with nonpolar solvent over the concentration range by varying temperature from $303 \mathrm{~K}$ to $288 \mathrm{~K}$. The changes in dielectric and relaxation parameters are associated with frequency, temperature and concentration. The conformation analyses of formation of hydrogen bonding between complex mixtures are identified using FT-IR spectra.

\section{Experimental Details}

\subsection{Materials, measurements and data analysis}

Stearic acid was procured from Sigma Aldrich with 99\% purity. Benzene and $n$-hexanol were obtained from Merck and LOBO with purity. The complex permittivity spectra were measured using Time Domain Reflectometry (TDR). ${ }^{24}$ Considerable dielectric relaxation work has been carried out using TDR. ${ }^{19-21,23}$ The Fourier transformation of the pulse and data analysis were done earlier to determine complex permittivity spectra $\varepsilon^{*}(\omega)$ using nonlinear least squares fit method. ${ }^{25-28}$ Our earlier works clearly explain the data analysis section to obtain dielectric and relaxation parameters. ${ }^{19,20,23}$ The FT-IR spectra were recorded in the range $400-4000 \mathrm{~cm}^{-1}$.

\section{Results and Discussion}

The values of dielectric parameters and relaxation time are obtained by a nonlinear least square fit method which are shown in Tables 1-3. One can conclude that the correlation function is supplemented by two types of contributions of dipolar and dielectric properties. The individual molecular dipole moments are transient or interaction induced and the relative correlation is distressed. Increase of dielectric parameter and relaxation time with decrease of temperature is due to the high intrinsic viscosity which leads to longer relaxation time and little dipole orientation. The fatty acid mixture viscosity and relaxation time decrease leading to an increase in dipole ordering and decrease in $\varepsilon^{\prime}$ and $\varepsilon^{\prime \prime}$ as the temperature increases. It is implicit that the temperaturedependent factor of fatty acid decreases with the increase of $n$-hexanol concentration as shown in Figs. 1-3.

Complex permittivity spectra $\varepsilon^{*}(\omega)$ was obtained from reflection coefficient $\rho^{*}(\omega)$ by applying a bilinear calibration method as per Eqs. (1) and (2):

$$
\rho^{*}(\omega)=\frac{c p(\omega)}{j \omega d q(\omega)} .
$$

The experimental values of $\varepsilon^{*}(\omega)$ fitted with Debye equation by distribution parameters $\alpha=0 ; \beta=1$ to obtain single
Table 1. Static dielectric constant $\left(\varepsilon_{0}\right)$, high frequency limiting dielectric constant $\left(\varepsilon_{\infty}\right)$, dielectric permittivity $\left(\varepsilon^{\prime}\right)$, dielectric loss $\left(\varepsilon^{\prime \prime}\right)$ and relaxation time $(\tau)$ for ternary mixtures of stearic acid at different temperatures.

\begin{tabular}{|c|c|c|c|c|c|c|}
\hline \multicolumn{4}{|c|}{$(($ Stearic Acid + Benzene)[0.039 Vol.\%]) } & \multicolumn{3}{|c|}{$0.1 \mathrm{MPa}$} \\
\hline $\begin{array}{l}(V / V) \% \\
\text { Hexanol }\end{array}$ & Temp $\left({ }^{\circ} \mathrm{C}\right)$ & $\varepsilon_{0}$ & $\varepsilon_{\infty}$ & $\varepsilon^{\prime}$ & $\varepsilon^{\prime \prime}$ & $\tau(\mathrm{ps})$ \\
\hline \multirow[t]{4}{*}{0.1} & 30 & 2.559 & 2.056 & 2.163 & 0.175 & 183.38 \\
\hline & 25 & 2.709 & 2.211 & 2.308 & 0.209 & 194.74 \\
\hline & 20 & 2.741 & 2.265 & 2.389 & 0.151 & 201.69 \\
\hline & 15 & 3.238 & 2.609 & 2.715 & 0.218 & 180.73 \\
\hline \multirow[t]{4}{*}{0.3} & 30 & 2.565 & 2.086 & 2.180 & 0.181 & 186.62 \\
\hline & 25 & 2.776 & 2.216 & 2.339 & 0.219 & 196.05 \\
\hline & 20 & 2.782 & 2.288 & 2.398 & 0.155 & 202.14 \\
\hline & 15 & 3.287 & 2.623 & 2.788 & 0.224 & 181.33 \\
\hline \multirow[t]{4}{*}{0.5} & 30 & 2.605 & 2.108 & 2.214 & 0.189 & 189.42 \\
\hline & 25 & 2.814 & 2.221 & 2.421 & 0.229 & 197.42 \\
\hline & 20 & 2.840 & 2.310 & 2.436 & 0.159 & 203.45 \\
\hline & 15 & 3.291 & 2.710 & 2.815 & 0.230 & 182.66 \\
\hline \multirow[t]{4}{*}{0.7} & 30 & 2.647 & 2.118 & 2.224 & 0.225 & 191.87 \\
\hline & 25 & 2.844 & 2.226 & 2.229 & 0.237 & 199.12 \\
\hline & 20 & 2.897 & 2.315 & 2.455 & 0.179 & 204.51 \\
\hline & 15 & 3.316 & 2.721 & 2.835 & 0.239 & 183.67 \\
\hline \multirow[t]{4}{*}{0.9} & 30 & 2.501 & 2.013 & 2.111 & 0.188 & 185.40 \\
\hline & 25 & 2.603 & 2.110 & 2.219 & 0.195 & 190.21 \\
\hline & 20 & 2.637 & 2.120 & 2.235 & 0.190 & 200.01 \\
\hline & 15 & 3.258 & 2.426 & 2.604 & 0.207 & 182.67 \\
\hline \multirow[t]{4}{*}{1.0} & 30 & 2.414 & 1.966 & 2.063 & 0.173 & 183.65 \\
\hline & 25 & 2.536 & 2.057 & 2.162 & 0.186 & 187.57 \\
\hline & 20 & 2.604 & 2.103 & 2.202 & 0.174 & 189.40 \\
\hline & 15 & 2.982 & 2.386 & 2.530 & 0.199 & 180.65 \\
\hline
\end{tabular}

relaxation time distribution showing Debye behavior

$$
\varepsilon^{*}(\omega)=\varepsilon_{\infty}+\frac{\left(\varepsilon_{0}-\varepsilon_{\infty}\right)}{\left[1+(j \omega \tau)^{1-\alpha}\right]^{\beta}} .
$$

The relaxation time decreases on decreasing temperature, on the other side, by increasing molar concentration, it enhances gradually on both binary and ternary systems due to the degree of unsaturation between $0.03 \mathrm{~mol} / \mathrm{L}$ and $0.07 \mathrm{~mol} / \mathrm{L}$. There is a gradual increase in relaxation time in addition of $n$-hexanol. Fig. 4 shows the relaxation time increases linearly with concentration above $0.07 \mathrm{ml} / \mathrm{L}$ since the solution becomes denser, reported in our earlier work. ${ }^{19}$ The dispersion was assigned to hydrophobic segment and the relaxation is receptive to changes in structure rotating as single unit. It shows that a freely rotating polar group component does not lie along the axis of group rotation. On increasing temperature, relaxation time decreases, i.e., the molecular relaxation time is affected by inter and intramolecular hydrogen bonding. This may possibly due to the increase in the molar volume and effective length of a dipole with an increase in temperature and also due to an increased thermal vibration or 
Table 2. Static dielectric constant $\left(\varepsilon_{0}\right)$, high frequency limiting dielectric constant $\left(\varepsilon_{\infty}\right)$, dielectric permittivity $\left(\varepsilon^{\prime}\right)$, dielectric loss $\left(\varepsilon^{\prime \prime}\right)$ and relaxation time $(\tau)$ for ternary mixtures of stearic acid at different temperatures.

\begin{tabular}{|c|c|c|c|c|c|c|}
\hline \multicolumn{4}{|c|}{$(($ Stearic Acid + Benzene)[0.197 Vol.\%]) } & \multicolumn{3}{|c|}{$0.1 \mathrm{MPa}$} \\
\hline $\begin{array}{l}(V / V) \% \\
\text { Hexanol }\end{array}$ & Temp $\left({ }^{\circ} \mathrm{C}\right)$ & $\varepsilon_{0}$ & $\varepsilon_{\infty}$ & $\varepsilon^{\prime}$ & $\varepsilon^{\prime \prime}$ & $\tau(\mathrm{ps})$ \\
\hline \multirow[t]{4}{*}{0.1} & 30 & 2.598 & 1.966 & 2.094 & 0.193 & 189.30 \\
\hline & 25 & 2.581 & 2.005 & 2.172 & 0.186 & 195.31 \\
\hline & 20 & 2.605 & 2.104 & 2.277 & 0.175 & 196.90 \\
\hline & 15 & 2.781 & 2.215 & 2.386 & 0.222 & 146.20 \\
\hline \multirow[t]{4}{*}{0.3} & 30 & 2.606 & 2.021 & 2.137 & 0.209 & 196.60 \\
\hline & 25 & 2.611 & 2.060 & 2.183 & 0.197 & 203.10 \\
\hline & 20 & 2.661 & 2.089 & 2.248 & 0.200 & 204.70 \\
\hline & 15 & 2.782 & 2.122 & 2.449 & 0.218 & 147.80 \\
\hline \multirow[t]{4}{*}{0.5} & 30 & 2.647 & 1.978 & 2.174 & 0.208 & 199.18 \\
\hline & 25 & 2.704 & 2.109 & 2.204 & 0.216 & 209.10 \\
\hline & 20 & 2.742 & 2.095 & 2.210 & 0.222 & 210.12 \\
\hline & 15 & 2.741 & 2.254 & 2.483 & 0.238 & 150.20 \\
\hline \multirow[t]{4}{*}{0.7} & 30 & 2.685 & 2.005 & 2.194 & 0.196 & 202.87 \\
\hline & 25 & 2.457 & 2.038 & 2.340 & 0.199 & 210.79 \\
\hline & 20 & 2.668 & 2.109 & 2.387 & 0.210 & 213.15 \\
\hline & 15 & 2.859 & 2.204 & 2.486 & 0.250 & 157.62 \\
\hline \multirow[t]{4}{*}{0.9} & 30 & 2.585 & 2.019 & 2.204 & 0.201 & 195.40 \\
\hline & 25 & 2.692 & 2.121 & 2.223 & 0.211 & 209.85 \\
\hline & 20 & 2.762 & 2.165 & 2.284 & 0.220 & 205.96 \\
\hline & 15 & 2.936 & 2.296 & 2.555 & 0.255 & 146.77 \\
\hline \multirow[t]{4}{*}{0.1} & 30 & 2.492 & 2.023 & 2.217 & 0.204 & 192.36 \\
\hline & 25 & 2.630 & 2.080 & 2.224 & 0.213 & 203.04 \\
\hline & 20 & 2.707 & 2.191 & 2.326 & 0.219 & 202.69 \\
\hline & 15 & 3.021 & 2.381 & 2.650 & 0.253 & 137.83 \\
\hline
\end{tabular}

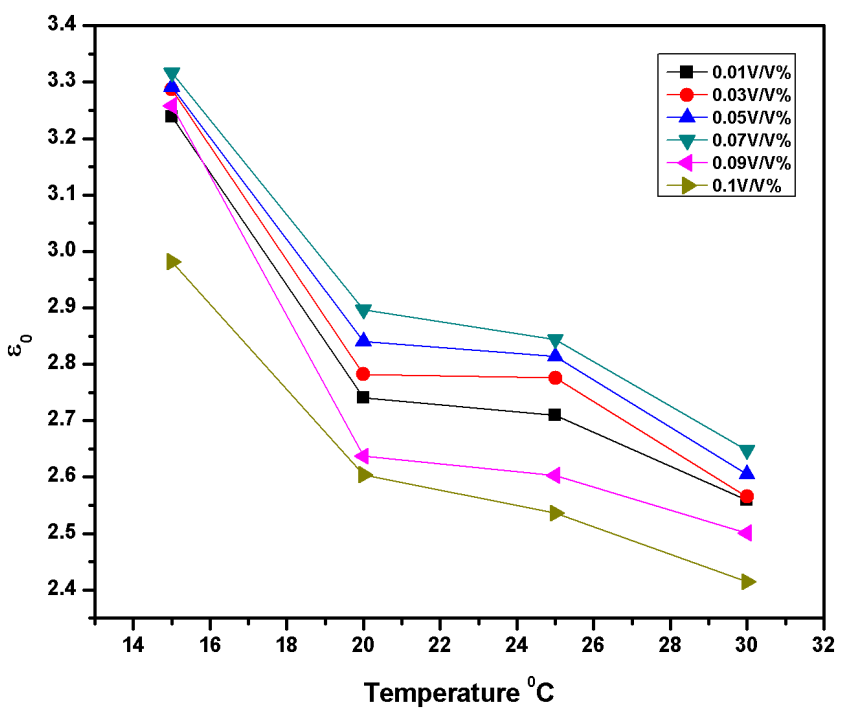

Fig. 1. The plot between stearic acid complexes 0.039 Vol.\% versus static dielectric constant for various concentrations and temperatures.
Table 3. Static dielectric constant $\left(\varepsilon_{0}\right)$, high frequency limiting dielectric constant $\left(\varepsilon_{\infty}\right)$, dielectric permittivity $\left(\varepsilon^{\prime}\right)$, dielectric loss $\left(\varepsilon^{\prime \prime}\right)$ and relaxation time $(\tau)$ for ternary mixtures of stearic acid at different temperatures.

\begin{tabular}{|c|c|c|c|c|c|c|}
\hline \multicolumn{4}{|c|}{$(($ Stearic Acid + Benzene $)[0.390$ Vol.\%] $)$} & \multicolumn{3}{|c|}{$0.1 \mathrm{MPa}$} \\
\hline $\begin{array}{l}(V / V) \% \\
\text { Hexanol }\end{array}$ & Temp $\left({ }^{\circ} \mathrm{C}\right)$ & $\varepsilon_{0}$ & $\varepsilon_{\infty}$ & $\varepsilon^{\prime}$ & $\varepsilon^{\prime \prime}$ & $\tau(\mathrm{ps})$ \\
\hline \multirow[t]{4}{*}{0.1} & 30 & 2.455 & 2.011 & 2.143 & 0.202 & 178.56 \\
\hline & 25 & 2.539 & 2.029 & 2.186 & 0.209 & 187.12 \\
\hline & 20 & 2.604 & 2.077 & 2.218 & 0.223 & 189.77 \\
\hline & 15 & 3.017 & 2.593 & 2.418 & 0.253 & 167.07 \\
\hline \multirow[t]{4}{*}{0.3} & 30 & 2.495 & 2.023 & 2.156 & 0.266 & 181.47 \\
\hline & 25 & 2.608 & 2.136 & 2.248 & 0.284 & 182.13 \\
\hline & 20 & 2.704 & 2.297 & 2.318 & 0.295 & 187.77 \\
\hline & 15 & 3.209 & 2.448 & 2.508 & 0.312 & 179.36 \\
\hline \multirow[t]{4}{*}{0.5} & 30 & 2.507 & 2.079 & 2.193 & 0.244 & 185.59 \\
\hline & 25 & 2.536 & 2.099 & 2.212 & 0.295 & 187.36 \\
\hline & 20 & 2.596 & 2.116 & 2.227 & 0.255 & 194.22 \\
\hline & 15 & 2.859 & 2.247 & 2.473 & 0.316 & 180.63 \\
\hline \multirow[t]{4}{*}{0.7} & 30 & 2.503 & 2.017 & 2.184 & 0.232 & 188.37 \\
\hline & 25 & 2.601 & 2.067 & 2.224 & 0.241 & 189.91 \\
\hline & 20 & 2.608 & 2.149 & 2.320 & 0.261 & 190.59 \\
\hline & 15 & 2.741 & 2.408 & 2.566 & 0.311 & 180.63 \\
\hline \multirow[t]{4}{*}{0.9} & 30 & 2.426 & 2.060 & 2.199 & 0.224 & 186.34 \\
\hline & 25 & 2.595 & 2.146 & 2.236 & 0.237 & 187.47 \\
\hline & 20 & 2.589 & 2.152 & 2.247 & 0.249 & 188.28 \\
\hline & 15 & 2.609 & 2.316 & 2.543 & 0.299 & 178.74 \\
\hline \multirow[t]{4}{*}{0.1} & 30 & 2.469 & 2.041 & 2.207 & 0.227 & 182.20 \\
\hline & 25 & 2.588 & 2.139 & 2.236 & 0.179 & 188.49 \\
\hline & 20 & 2.577 & 2.220 & 2.324 & 0.199 & 189.90 \\
\hline & 15 & 2.573 & 2.414 & 2.552 & 0.310 & 175.90 \\
\hline
\end{tabular}

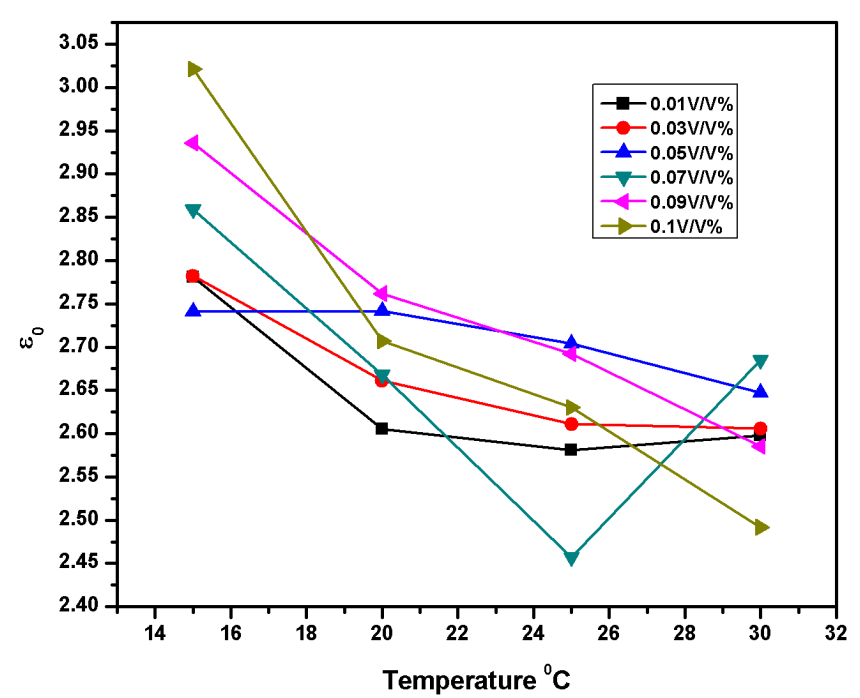

Fig. 2. The plot between stearic acid complexes 0.197 Vol.\% versus static dielectric constant for various concentrations and temperatures. 


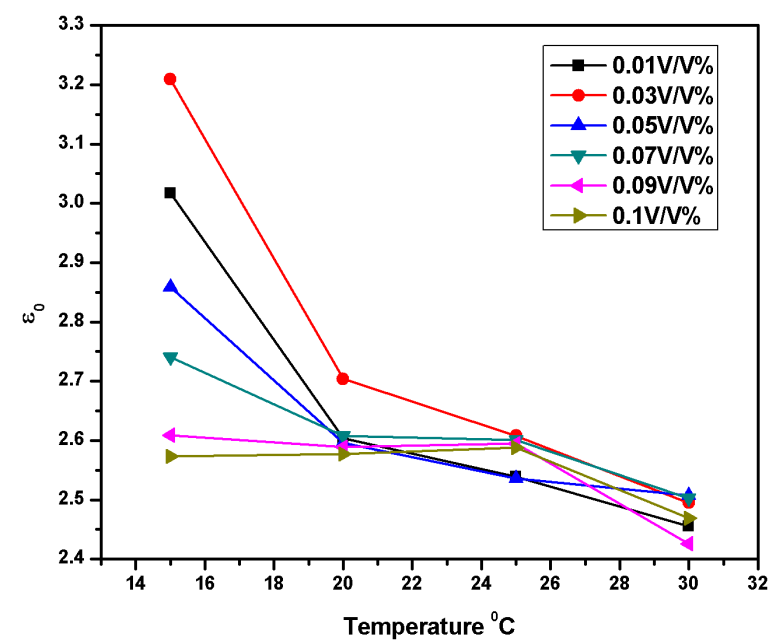

Fig. 3. The plot between stearic acid complexes 0.39 Vol.\% versus static dielectric constant for various concentrations and temperatures.

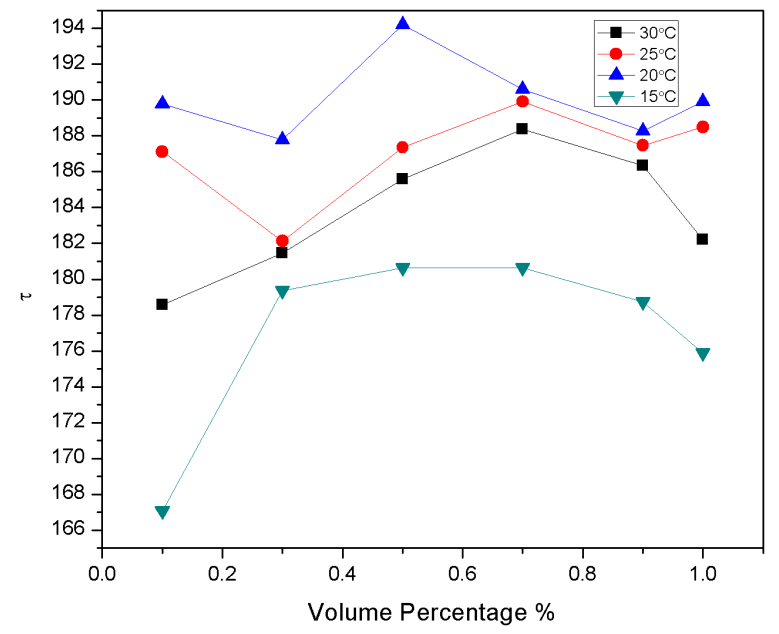

Fig. 4. The plot between stearic acid complexes versus relaxation time (ps) for various concentrations and temperatures.

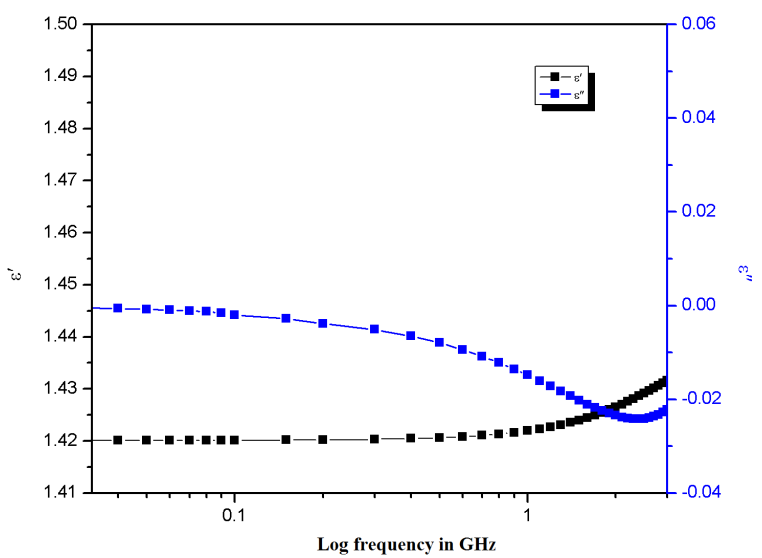

Fig. 5. The complex dielectric spectra of stearic acid complexes versus $\log$ frequency for $0.390 \mathrm{Vol} \%$ of binary mixture. agitation and partially due to a decrease in the viscous nature of the molecules.

Further, the addition of third component substantially increases the viscosity of solution and their influential changes in relaxation time $(\tau)$. The dielectric parameters and relaxation time decrease due to the splitting of intramolecular interaction and decrease in shear viscosity of the solution.

The dielectric permittivity values of stearic acid compo-

Table 4. Enthalpy, entropy of activation and Gibb's free energy for ternary mixture of stearic acid complex.

\begin{tabular}{|c|c|c|c|c|}
\hline & $V / V \%$ & $\Delta H(\mathrm{KJ} / \mathrm{mol})$ & $\Delta S(\mathrm{KJ} / \mathrm{mol})$ & $\Delta G(\mathrm{KJ} / \mathrm{mol})$ \\
\hline \multirow{7}{*}{$\begin{array}{l}\mathrm{SA}+\mathrm{BEN} \\
\quad(0.039 \mathrm{Vol} . \%)\end{array}$} & HEX & & & \\
\hline & 0.1 & -2.6428 & 4.0819 & -1.2394 \\
\hline & 0.3 & -3.3409 & 3.8069 & -1.1568 \\
\hline & 0.5 & -3.6741 & 3.6355 & -1.1052 \\
\hline & 0.7 & -4.0401 & 3.5232 & -1.0715 \\
\hline & 0.9 & -2.4298 & 3.1518 & -0.9574 \\
\hline & 1.0 & -3.0650 & 1.6190 & -0.4936 \\
\hline \multirow{7}{*}{$\begin{array}{l}\mathrm{SA}+\mathrm{BEN} \\
\quad(0.123 \mathrm{Vol} . \%)\end{array}$} & HEX & & & \\
\hline & 0.1 & -12.754 & 3.295 & -1011.14 \\
\hline & 0.3 & -15.658 & 3.0032 & -925.627 \\
\hline & 0.5 & -15.032 & 3.2475 & -999.025 \\
\hline & 0.7 & -15.325 & 5.092 & -1558.2 \\
\hline & 0.9 & -17.015 & 3.5266 & -1085.57 \\
\hline & 1.0 & -12.436 & 6.0472 & -1844.74 \\
\hline \multirow{7}{*}{$\begin{array}{l}\text { SA + BEN } \\
\quad(0.197 \text { Vol.\%) }\end{array}$} & HEX & & & \\
\hline & 0.1 & -13.743 & 7.959 & -2425.32 \\
\hline & 0.3 & -15.114 & 8.7705 & -2672.58 \\
\hline & 0.5 & -14.956 & 9.0989 & -2771.92 \\
\hline & 0.7 & -13.431 & 8.2185 & -2503.64 \\
\hline & 0.9 & -15.384 & 9.5538 & -2910.19 \\
\hline & 1.0 & -17.205 & 10.4714 & -3190.04 \\
\hline \multirow{7}{*}{$\begin{array}{l}\mathrm{SA}+\mathrm{BEN} \\
\quad(0.270 \text { Vol. } \%)\end{array}$} & HEX & & & \\
\hline & 0.1 & -14.241 & 7.2245 & -2203.26 \\
\hline & 0.3 & -14.958 & 8.4833 & -2585.4 \\
\hline & 0.5 & -14.002 & 8.0849 & -2463.73 \\
\hline & 0.7 & -14.201 & 7.7962 & -2376.45 \\
\hline & 0.9 & -14.456 & 3.4292 & -1053.5 \\
\hline & 1.0 & -16.397 & 3.6828 & -1132.29 \\
\hline \multirow{4}{*}{$\begin{array}{l}\mathrm{SA}+\mathrm{BEN} \\
\quad(0.350 \mathrm{Vol} . \%)\end{array}$} & HEX & & & \\
\hline & 0.1 & -3.4601 & 3.5932 & -1092.2 \\
\hline & 0.3 & -3.604 & 3.0379 & -924.088 \\
\hline & 0.5 & -0.1668 & 0.1994 & -60.585 \\
\hline \multirow{10}{*}{$\begin{array}{l}\mathrm{SA}+\mathrm{BEN} \\
\quad(0.390 \mathrm{Vol} . \%)\end{array}$} & 0.7 & -1.8493 & 0.1642 & -51.6019 \\
\hline & 0.9 & -1.7272 & 0.2425 & -75.2047 \\
\hline & 1.0 & -3.1002 & 0.7694 & -236.228 \\
\hline & HEX & & & \\
\hline & 0.1 & -5.2319 & 4.1082 & -1250.02 \\
\hline & 0.3 & -2.381 & 1.6461 & -501.149 \\
\hline & 0.5 & -2.7479 & 2.5426 & -773.156 \\
\hline & 0.7 & -4.2601 & 1.4871 & -454.851 \\
\hline & 0.9 & -4.2337 & 1.4148 & -432.918 \\
\hline & 1.0 & -0.1575 & 0.1661 & -50.4858 \\
\hline
\end{tabular}


sition strongly depend on the solvent nature. On increasing the concentration of binary from $0.01 \mathrm{~mol} / \mathrm{L}$ to $0.1 \mathrm{~mol} / \mathrm{L}$, dielectric permittivity decreases up to $0.05 \mathrm{~mol} / \mathrm{L}$ and then increases. The initial decrement of dielectric permittivity is expected with the limited interaction between molecules in the frequency dispersion curve as shown in Fig. 5. The dielectric loss increases on reducing the temperature and decreases on increasing solute concentration at the lower frequency region of dispersion spectra. Enhancing the concentration of binary above $0.05 \mathrm{~mol} / \mathrm{L}$, the dielectric permittivity increases significantly. This may be due to solute coagulation or cluster formation taking place which denotes the alternating trend of relaxation time. At the higher concentration of the mixtures, the co-solvent alters the dielectric relaxation time due to (i) mutual solubility (ii) homogeneous number of solute molecules gathering and (iii) distributed interaction of solute-solvent. Thus, dielectric value shows relatively high at lower frequency region $(\mathrm{MHz})$ and reaches a stable value at $8 \mathrm{GHz}$ concluding the interaction between the fatty acid and alcohol molecules in moderate rate. This can be represented as a function of frequency and slight modification in spectrum by changing the solute concentration. ${ }^{19}$ Above $8 \mathrm{GHz}$, the dispersion spectrum of $\varepsilon^{\prime}$ and $\varepsilon^{\prime \prime}$ were superimposed with each other. The spacing between the dielectric values in dispersion spectrum could be attributed to the relative percentage of solute-solvent interaction with more clusters formed in mixture.

The thermodynamic parameters which are evaluated using Eyring equation is given as follows:

$$
\tau=(h / K T) \exp (\Delta H / R T) \exp (-\Delta S / R) .
$$

The chemical changes during the reaction can be expected as absorption process in chemical thermodynamics associated to three main parameters such as Gibb's free energy $(\Delta G)$, enthalpy of activation $(\Delta H)$ and entropy of activation $(\Delta S)$ as reported in Table 4. The Gibb's energy change is the driving force and the fundamental criterion of spontaneity. ${ }^{29-34}$ Physical absorption is to be a spontaneous thermodynamic process with negative value. The thermodynamic parameters of adsorption relaxation strength $(\Delta \varepsilon)$ and dielectric activation $(\Delta F)$ of binary complexes have been calculated and the results are tabulated in Table 5 using this formula $\Delta \varepsilon=\varepsilon_{0}-\varepsilon_{\infty}$ and $\Delta F=\varepsilon_{0}-\varepsilon^{\prime} \cdot{ }^{35,36}$ The Gibb's free energy is to be negative only if there is absorption of thermal energy by complexes of the mixture. The enthalpy $(\Delta H)$ is negative and entropy $(\Delta S)$ is positive, respectively, since the enthalpy is confirmed that the absorption of binary complexes is an exothermic process. This can

Table 5. Excess permittivity, dielectric strength and activation energy of stearic acid complex at different temperatures.

\begin{tabular}{|c|c|c|c|c|c|c|c|c|c|c|}
\hline \multirow[b]{2}{*}{ Temp. } & \multirow[b]{2}{*}{$V / V \%$} & \multicolumn{3}{|c|}{$0.039 \mathrm{SA}$} & \multicolumn{3}{|c|}{$0.197 \mathrm{SA}$} & \multicolumn{3}{|c|}{$0.390 \mathrm{SA}$} \\
\hline & & $\varepsilon^{E}$ & $\Delta \epsilon$ & $\Delta F$ & $\varepsilon^{E}$ & $\Delta \epsilon$ & $\Delta F$ & $\varepsilon^{E}$ & $\Delta \epsilon$ & $\Delta F$ \\
\hline \multirow[t]{6}{*}{30} & 0.1 & -0.076 & 0.396 & 0.503 & -0.0882 & 0.504 & 0.632 & -0.0827 & 0.312 & 0.444 \\
\hline & 0.3 & -0.2861 & 0.385 & 0.479 & -0.294 & 0.469 & 0.585 & -0.2601 & 0.339 & 0.472 \\
\hline & 0.5 & -0.461 & 0.391 & 0.497 & -0.468 & 0.473 & 0.699 & -0.4654 & 0.314 & 0.428 \\
\hline & 0.7 & -0.635 & 0.423 & 0.529 & -0.6444 & 0.491 & 0.68 & -0.6869 & 0.319 & 0.486 \\
\hline & 0.9 & -0.99 & 0.39 & 0.488 & -0.9588 & 0.381 & 0.566 & -0.9813 & 0.227 & 0.366 \\
\hline & 1.0 & -1.191 & 0.351 & 0.448 & -1.159 & 0.275 & 0.469 & -1.047 & 0.262 & 0.428 \\
\hline \multirow[t]{6}{*}{25} & 0.1 & -0.0494 & 0.401 & 0.498 & -0.2294 & 0.409 & 0.576 & -0.1986 & 0.353 & 0.51 \\
\hline & 0.3 & -0.1954 & 0.437 & 0.56 & -0.4118 & 0.428 & 0.551 & -0.343 & 0.36 & 0.472 \\
\hline & 0.5 & -0.3704 & 0.393 & 0.593 & -0.5307 & 0.5 & 0.595 & -0.6284 & 0.324 & 0.437 \\
\hline & 0.7 & -0.553 & 0.615 & 0.618 & -0.9896 & 0.117 & 0.419 & -0.7768 & 0.377 & 0.534 \\
\hline & 0.9 & -1.007 & 0.384 & 0.493 & -0.9665 & 0.469 & 0.571 & -0.9962 & 0.359 & 0.449 \\
\hline & 1.0 & -1.8079 & 0.374 & 0.479 & -1.1344 & 0.406 & 0.55 & -1.1098 & 0.352 & 0.449 \\
\hline \multirow[t]{6}{*}{20} & 0.1 & -0.0798 & 0.352 & 0.476 & -0.2831 & 0.328 & 0.501 & -0.2109 & 0.386 & 0.527 \\
\hline & 0.3 & -0.2505 & 0.384 & 0.494 & -0.437 & 0.413 & 0.572 & -0.3227 & 0.386 & 0.407 \\
\hline & 0.5 & -0.4042 & 0.404 & 0.53 & -0.5668 & 0.532 & 0.647 & -0.6425 & 0.369 & 0.48 \\
\hline & 0.7 & -0.5589 & 0.442 & 0.582 & -0.8511 & 0.281 & 0.559 & -0.8423 & 0.288 & 0.459 \\
\hline & 0.9 & -1.0306 & 0.402 & 0.517 & -0.9675 & 0.478 & 0.597 & -1.0731 & 0.342 & 0.437 \\
\hline & 1.0 & -1.1694 & 0.402 & 0.501 & -1.1276 & 0.381 & 0.516 & -1.1911 & 0.253 & 0.357 \\
\hline \multirow[t]{6}{*}{15} & 0.1 & -0.1171 & 0.523 & 0.629 & -0.3715 & 0.395 & 0.566 & -0.1118 & 0.791 & 0.616 \\
\hline & 0.3 & -0.0354 & 0.503 & 0.668 & -0.6165 & 0.292 & 0.619 & -0.5024 & 0.509 & 0.569 \\
\hline & 0.5 & -0.2450 & 0.472 & 0.577 & -0.7804 & 0.299 & 0.528 & -0.9801 & 0.268 & 0.494 \\
\hline & 0.7 & -0.421 & 0.481 & 0.595 & -0.9085 & 0.373 & 0.655 & -1.063 & 0.293 & 0.451 \\
\hline & 0.9 & -0.8853 & 0.454 & 0.632 & -0.9515 & 0.466 & 0.725 & -1.5154 & 0.066 & 0.293 \\
\hline & 1.0 & -1.0619 & 0.452 & 0.596 & -1.1389 & 0.286 & 0.555 & -1.6523 & 0.021 & 0.159 \\
\hline
\end{tabular}




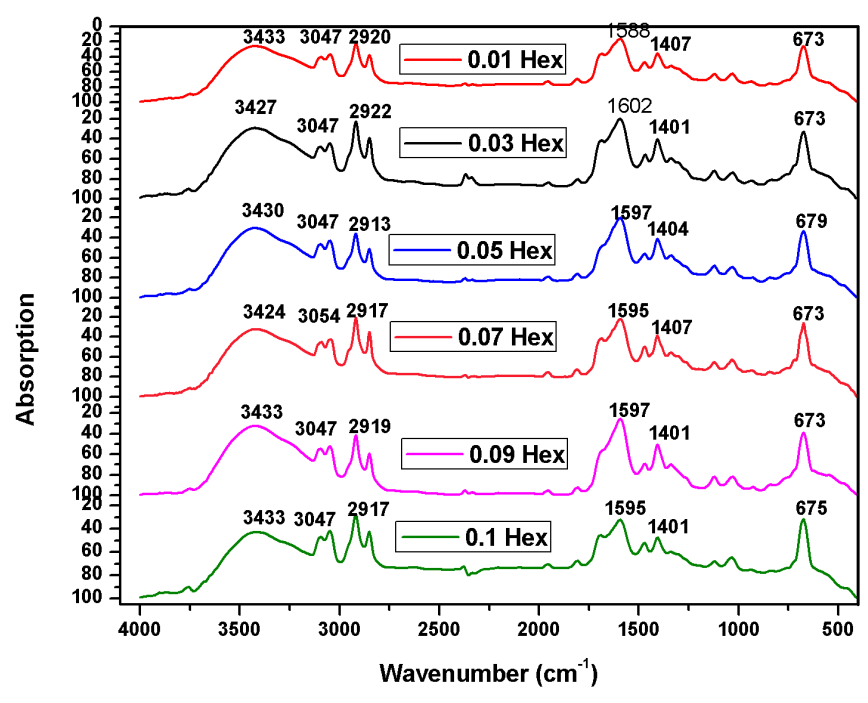

Fig. 6. FT-IR spectra of stearic acid in solution state for various concentrations and temperatures.

be due to the energy released after the adsorption process. The negative value of enthalpy indicates that the process is exothermic and the physical absorption behavior in nature can be easily reversed by supplying the heat equal to the absorption system. The positive value of entropy suggests the random orientation in solute-solvent complex or interface between solid and solution during the absorption. $\Delta S$ increases spontaneously in favor of molecular movement. The negative value of enthalpy and positive value of entropy signify that molecular dipoles are spontaneously aligned and oriented at all temperatures.

The FT-IR spectroscopic technique is used to provide the possible interaction between the mixtures of adsorbent during an adsorption process. ${ }^{37}$ The $\mathrm{C}=\mathrm{O}$ stretching frequency of the stearic acid appears at $1700.22 \mathrm{~cm}^{-1}$ as shown in Fig. 6 . This absorption value gradually increases for a particular wave number on increasing the concentration. This confirms the presence of carboxylic acid. The strong bands at $2915 \mathrm{~cm}^{-1}$ and $2852 \mathrm{~cm}^{-1}$ are assigned to symmetric and asymmetric stretching modes of the $\mathrm{CH}_{2}$ groups. After absorption, this strong band disappears whereas a weaker band appears at $1628.03 \mathrm{~cm}^{-1}$. In addition, the hydrophobic chain of the stearic acid is not involved in the absorption process because the $\mathrm{C}-\mathrm{H}$ vibration frequencies at $2923.56 \mathrm{~cm}^{-1}$ and $2856.06 \mathrm{~cm}^{-1}$ are essentially unchanged on absorption compared to the free stearic acid. With increasing concentration, intensity of absorption $\mathrm{C}-\mathrm{H}$ increases, and shows that $\mathrm{C}-\mathrm{H}$ vibration is conformed for all concentrations. The band of the singlet shape $1467 \mathrm{~cm}^{-1}$ with symmetrical line shape shifts to $1472 \mathrm{~cm}^{-1}$ on increasing the concentration of the solution. There is no change in the absorption value of particular wave number. It has been established that the $\mathrm{CH}_{2}$ scissoring vibration forms in solution.

\section{Conclusions}

The dispersion dielectric analysis concludes that saturated fatty acids show stearic hindrance repulsion for molecules with nonpolar solvents. The dielectric and relaxation behavior of binary ${ }^{19}$ is different from ternary with alcohol as co-solvent. The interaction between solute-solvent and co-solvent makes it cause the effective attraction between the molecules. In the higher concentration of binary, a considerable amount of aggregates or clusters are formed which leads to change in relaxation time. The molecular attraction between the molecules shifts the transition point into a liquid-crystal state on the side of lower concentration. An important conclusion can also be made between solute and solvent interactions connected with a special arrangement of benzene molecule on the acid surface. As the size of the solvent molecules are comparatively smaller than solute, the dielectric parameter varies with respect to frequency, temperature and concentration. The dielectric dispersion spectrum exhibits a general plateau and the maximum dielectric values at lower frequencies altered significantly at dielectric dispersion area. The static dielectric constant increases gradually with concentration and decreases to a minimum with their permittivity. Dielectric, thermodynamic parameters and relaxation time are gradually increased with the decrease in temperature. Higher internal viscosity leads to longer relaxation time and smaller dipolar orientation. The negative value of Gibb's energy indicates that the chemical potential is minimized by thermal absorption of binary complexes. The enthalpy and entropy are negative and positive values, respectively, since the complex system is exothermic in nature. The positive value of entropy significantly suggests solute-solvent interaction or interface between solid and solution during absorption. The FT-IR spectrum proven to be the adsorption is carried out by the possible interaction between the stearic acid molecule and hydrogen bonding on the surface of benzene.

\section{References}

${ }^{1}$ Y. Feldman, A. Puzenko and Y. Ryabov, Non-Debye dielectric relaxation in complex materials, Chem. Phys. 284, 139 (2002).

${ }^{2}$ D. Vollhardt and U. Retter, Growth of Preformed 3D nuclei in Langmuir monolayers below critical supersaturation, Langmuir 14, 7250 (1998).

${ }^{3}$ A. Angelova, D. Vollhardt and R. Lonov, 2D-3D Transformations of amphiphilic monolayers influenced by intermolecular interactions: A Brewster angle microscopy study, J. Phys. Chem. 100, 10710 (1996).

${ }^{4}$ D. K. Schwartz, J. Garnaes, R. Viswanathan and J. A. N. Zasadzinski, Spontaneous chiral symmetry breaking by achiral molecules in a Langmuir-Blodgett film, Science 257, 508 (1992).

${ }^{5}$ A. L. Fameau, J. P. Douliez, F. Boue, F. Ott and F. Cousin, Adsorption of multilamellar tubes with a temperature tunable diameter at the air/water interface, J. Colloid Interface Sci. 362, 397 (2011). 
${ }^{6}$ A. L. Fameau, S. Lam and O. D. Velev, Multi-stimuli responsive foams combining particles and self-assembling fatty acids, Chem. Sci. 4, 3874 (2013).

${ }^{7}$ A. L. Fameau, A. Saint-Jalmes, F. Cousin, B. H. Houssou, B. Novales, L. Navailles et al., Smart foams: Switching reversibly between ultrastable and unstable foams, Angew. Chem. Int. Ed. 50, 8264 (2011).

${ }^{8}$ K. Morigaki and P. Walde, Fatty acid vesicles, Curr. Opin. Colloid Interface Sci. 12, 75 (2007).

${ }^{9}$ R. H. Cole, IEEE Trans. Instrum. Meas. 32, 42 (1983).

${ }^{10} \mathrm{~V}$. A. Rana and A. D. Vyas, Dielectric relaxation study of mixtures of 1-propanol with aniline, 2-chloroaniline and 3-chloroaniline at different temperatures using time domain reflectometry, J. Mol. Liq. 102, 379 (2002).

${ }^{11}$ T. Sato, A. Chiba and R. Nozaki, Composition-dependent dynamical structures of monohydric alcohol-water mixtures studied by microwave dielectric analysis, J. Mol. Liq. 96, 327 (2002).

${ }^{12}$ V. P. Pawar and S. C. Mehrotra, Dielectric relaxation study of dimethylene chloride with ethanol using time domain reflectometry, J. Mol. Liq. 108, 95 (2003).

${ }^{13}$ R. J. Sengwa, S. Sankhla, V. Khatri and S. Choudhary, Static permittivity and molecular interactions in binary mixtures of ethanolamine with alcohols and amides, Fluid Phase Equilib. 293, 137 (2010).

${ }^{14}$ C. P. Smyth, Molecular Interaction (John Wiley \& Sons, 1980).

${ }^{15}$ V. A. Rana and H. A. Chaube, Relative permittivity, density, viscosity, refractive index and ultrasonic velocity of binary mixture of ethylene glycol monophenyl ether and 1-hexanol at different temperatures, J. Mol. Liq. 187, 66 (2013).

${ }^{16}$ C. M. Kinart, A. Cwikinska, A. Baid and Z. Kinart, Studies on intermolecular interactions in (nitrobenzene + alkoxyethanol) binary mixtures by relative permittivity measurements at $T=$ (293.15, 298.15, 303.15, 308.15, and 313.15) K, J. Chem. Thermodyn. 50, 37 (2012).

${ }^{17}$ K. Sarojini and T. Thenappan, Dielectric studies of hydrogen bonded ternary systems: Acetonitrile + alcohols + benzene, J. Mol. Liq. 151, 39 (2010).

${ }^{18}$ R. J. Sengwa and S. Sankhla, Characterization of heterogeneous interaction in binary mixtures of ethylene glycol oligomer with water, ethyl alcohol and dioxane by dielectric analysis, J. Mol. Liq. 130, 119 (2007).

${ }^{19}$ M. MariaSylvester, T. Ganesh, D. J. S. Anand Karunakaran, P. Hudge and A. C. Kumbharkhane, Time domain dielectric relaxation studies of amphiphilics in solution state, J. Mol. Liq. 194, 57 (2014).

${ }^{20}$ D. J. S. Anand Karunakaran, T. Ganesh, M. Maria Sylvester, P. Hudge and A. C. Kumbharkhane, Dielectric properties and analysis of H-bonded interaction study in complex systems of binary and ternary mixtures of polyvinyl alcohol with water and DMSO, Fluid Phase Equilib. 382, 300 (2014).

${ }^{21}$ Y. S. Joshi and A. C. Kumbharakhane, Study of heterogeneous interaction in binary mixtures of 2-methoxyethanol-water using dielectric relaxation spectroscopy, J. Mol. Liq. 161, 120 (2011).

${ }^{22}$ A. C. Kumbharakhane, S. M. Puranik and S. C. Mehrotra, Temperature-dependent dielectric relaxation study of ethylene glycolwater mixtures, J. Solution. Chem. 21, 20 (1992).

${ }^{23}$ D. J. S. Anand Karunakaran, T. Ganesh, M. Maria Sylvester, P. Senthilkumar, P. Hudge and A. C. Kumbharkhane, Dielectric dispersion and molecular interaction in polymer (PVA)-surfactant (SDS) mixtures using picosecond time domain reflectometry, J. Mol. Liq. 224, 1199 (2016).

${ }^{24}$ S. M. Puranic, A. C. Kumbharkhane and S. C. Mehrotra, Dielectric properties of honey-water mixtures between $10 \mathrm{MHz}$ to $10 \mathrm{GHz}$ using time domain technique, J. Microw. Power Electromagn. Energy 26, 196 (1991).

${ }^{25}$ J. B. Hasted, Aqueous Dielectric (Chapman and Hall, London, 1973).

${ }^{26}$ S. D. Chavan, B. D. Watode, G. Hudge, D. B. Suryawanshi, C. G. Akode, A. C. Kumbharkhane and S. C. Mehrotra, Dielectric relaxation and hydrogen bond interaction study of diol-water mixtures, Indian J. Phys. 84, 419 (2010).

${ }^{27}$ A. C. Kumbharakhane, S. M. Puranik and S. C. Mehrotra, Dielectric relaxation of tert-butyl alcohol-water mixtures using a time-domain technique, Faraday Trans. 87, 1569 (1991).

${ }^{28}$ A. Chaudhari, A. G. Shankarwar, B. R. Arbad and S. C. Mehrotra, Dielectric relaxation in glycine-water and glycine-ethanol-water solutions using time domain reflectometry, J. Solution Chem. 33, 313 (2004).

${ }^{29}$ T. Indira, T. Thenappan and G. Parthipan, Temperature dependence of dielectric relaxation time and thermodynamic energy parameters of epichlorohydrin and 2-chlorophenol in benzene using the microwave technique, J. Chem. Thermodyn. 48, 243 (2012).

${ }^{30}$ A. K. Nain and M. Lather, Solute-solute and solute-solvent interactions of $l$-histidine and $l$-arginine in aqueous-streptomycin sulphate solutions at different temperatures: A physicochemical study, J. Mol. Liq. 211, 178 (2015).

${ }^{31}$ A. K. Nain, P. Droliya, J. Yadev and A. Agarwal, Physicochemical study of (solute+solute) and (solute+solvent) interaction of $L$. asparagine and $L$. glutamine in aqueous- $D$-mannose solutions at temperature from (293.15 to 318.15) K, J. Chem. Thermodyn. 95, 202 (2016).

${ }^{32}$ A. K. Nain, R. Pal and R. K. Sharma, Volumetric, ultrasonic, and viscometric behavior of $l$-histidine in aqueous-glucose solutions at different temperatures, J. Chem. Thermodyn. 43, 603 (2011).

${ }^{33}$ J. A. Rard, Critical evaluation of the standard molar entropies, enthalpies of formation, gibbs energies of formation and heat capacities of the aqueous trivalent rare earth ions, and the corresponding standard molar entropies, enthalpies of formation and gibbs energies of formation of the thermodynamically stable $\mathrm{RECl}_{3}{ }_{7} \mathrm{H}_{2} \mathrm{O}(\mathrm{cr})$ and $\mathrm{RECl} 33_{-} 6 \mathrm{H}_{2} \mathrm{O}(\mathrm{cr})$, J. Solution Chem. 45, 1332 (2016).

${ }^{34} \mathrm{~J}$. A. Rard, Isopiestic determination of the osmotic and activity coefficients of aqueous $\mathrm{Lu} 2\left(\mathrm{SO}_{4}\right)_{3}$ at $25^{\circ} \mathrm{C}, \mathrm{J}$. Solution Chem. 19, 525 (1990).

${ }^{35}$ M. Jaroszewski, J. J. Pospieszna and J. Ziaja, Dielectric properties of polypropylene fabrics with carbon plasma coatings for applications in the technique of electromagnetic field shielding, J. NonCryst. Solids 356, 625 (2010).

${ }^{36}$ T. S. Krishna, K. Narendra, M. G. Sankar, A. K. Nain and B. Munibhadrayya, Thermodynamic, excess and optical studies on the intermolecular interactions of binary liquid mixtures of imidazolium based ILs, J. Chem. Thermodyn. 98, 262 (2016).

${ }^{37}$ F. Adam and J. H. Chua, The adsorption of palmytic acid on rice husk ash chemically modified with $\mathrm{Al}(\mathrm{III})$ ion using the sol-gel technique, J. Colloid Interface Sci. 280, 55 (2004). 